\title{
KECUKUPAN KETERBUKAAN INFORMASI PUBLIK DALAM PERSPEKTIF TATA KELOLA PELAYANAN E-KTP DI KANTOR DINAS KEPENDUDUKAN DAN PENCATATAN SIPIL KABUPATEN KATINGAN
}

\author{
Adequacy of Public Information Openness in the Governance Perspective of e-KTP \\ Services at the Katingan Regency Population and Civil Registration Office
}

\section{Sabirin Muhtar* \\ Priadi}

\author{
Universitas Muhammadiyah \\ Palangkaraya, Palangka Raya, Central \\ Kalimantan, Indonesia \\ email: \\ sabirin.muhtar@umpalangkaraya.ac.id
}

\begin{abstract}
Abstrak
Penelitian ini bertujuan untuk menjelaskan dan mendeskripsikan tentang Kecukupan Keterbukaan Informasi Publik Dalam Perspektif Tata Kelola Pelayanan E-KTP Di Kantor Dinas Kependudukan Dan Pencacatan Sipil Kabupaten Katingan. Tipe penelitian yang digunakan adalah metode penelitian kualitatif, dimana teknik pengumpulan data melalui observasi, wawancara, dan dokumentasi.Analisa data menggunakan analisa data kualitatif, yaitu reduksi data, penyajian data, dan penarikan kesimpulan. Adapun data primer dalam penelitian ini sebagai informannya adalah pada bagian Pembuatan E-KTP (Kepala Bidang Pelayanan Pendaftaran Penduduk) di Dinas Kependudukan dan Pencatatan kabupaten katingan, dan Kepada Masyarakat kabupaten katingan dan Sumber Sekunder, yaitu sumber yang tidak langsung memberikan data kepada pengumpul data, data tersebut berasal dari bahan-bahan, baik berupa buku-buku, artikel, karya ilmiah yang di muat dalam media massa seperti majalah dan surat kabar, serta jurnal ilmiah. Berdasarkan hasil penelitian menggunakan teori Efektifitas berhubungan dengan kecukupan dapat dijelaskan bahwa Kecukupan Keterbukaan Informasi Publik Dalam Perspektif Tata Kelola Pelayanan E-KTP Di Kantor Dinas Kependudukan Dan Pencacatan Sipil Kabupaten Katingan masih memiliki beberapa perlu peningkataan dalam memberikan Keterbukaan Informasi Publik Dalam Perspektif tata kelola Pelayanan E-KTP, tentang efesiensi, kecukupan, perataan, responsivitas, ketepatan dalam memberikan keterbukaan informasi publik pembuatan jadi E-KTP.
\end{abstract}

Kata Kunci:

Kecukupan

Keterbukaan

Informasi Publik

Tata Kelola

Pelayanan

Keywords:

Adequacy

Openness

Public Information

Governance

Service

Accepted

June 2017

Published

October 2017

\begin{abstract}
This study aims to explain and describe the Sufficiency of Public Information Openness in the E-KTP Service Governance Perspective at the Katingan Regency Population and Civil Disablement Office. The type of research used is qualitative research methods, where data collection techniques are through observation, interviews, and documentation. Data analysis uses qualitative data analysis, namely data reduction, data presentation, and conclusion drawing. The primary data in this study as informants are in the Making of E-KTP (Head of Population Registration Services) in the Population and Registration Office of Katingan District, and Kepat Masyarakat of Katingan District and Secondary Sources, namely sources that do not directly provide data to data collectors, the data comes from materials, both in the form of books, articles, scientific works that are loaded in mass media such as magazines and newspapers, and scientific journals. Based on the results of the study using the theory of effectiveness related to the adequacy, it can be explained that the relevance of public information disclosure in the E-KTP Service Governance Perspective at the Katingan Regency Population and Civil Disability Service Office still has some need for improvement in providing Public Information Openness in the E-Service Governance perspective. KTP, about efficiency, adequacy, leveling, responsiveness, accuracy in providing public information disclosure to make E-KTP.
\end{abstract}

\section{PENDAHULUAN}

$\begin{array}{lcrrr}\text { E-KTP atau KTP Elektronik adalah dokumen } \\ \text { kependudukan yang } \quad \text { memuat } & \text { sistem } \\ \text { keamanan/pengendalian baik dari } & \text { sisi } & \text { administrasi }\end{array}$

ataupun teknologi informasi dengan berbasis pada database kependudukan nasional. Penduduk diperbolehkan memiliki I (satu) KTP yang tercantum Nomor Induk Kependudukan (NIK). 
Keterbukaan informasi publik sangat diperlukan oleh masyarakat publik, yang menjadikan berjalannya pelayanan yang efektif dan efesien adalah keterbukaan informasi publik dari pemerintahan di Kantor Dinas Kependudukan dan Pencacatan Sipil, Kabupaten Katingan, Provinsi Kalimantan Tengah.Pelayanan yang bersifat terbuka dalam memberikan informasi kepada publik akan membuat efektifitas dan efesiensi menjadi pelayanan yang baik. keterbukaan informasi publik bahwa informasi merupakan kebutuhan pokok setiap orang bagi pegembangan pribadi dan lingkungan sosialnya serta merupakan bagian penting bagi ketahanan sosial.

Keterbukaan informasi publik bahwa hak memperoleh informasi merupakan hak asasi manusia dan keterbukaan informasi publik merupakan salah satu ciri penting Negara demokratis yang menjunjung tinggi kedaulatanrakyat untuk mewujudkan penyelenggaraan Negara yang baik.

Bahwa keterbukaan informasi publik merupakan sarana dalam mengoptimalkan pengawasan publik lainnya dan segala sesuatu yang berakibat pada kepentingan publik, bahwa pengelolaan informasi publik merupakan salah satu upaya untuk mengembangkan masyarakat. Sedangkan Informasi Publik adalah informasi yang dihasilkan, disimpan, dikelola, dikirim, dan/atau penyelenggara dan penyelenggaraan Negara dan/atau penyelanggara dan penyelanggaraan badan publik lainya yang sesuai dengan tentang keterbukaan informasi publik ini, serta informasi lain yang berkaitan dengan kepentingan publik. informasi yang kurang memadai, alasan yang keliru, atau asumsi-asumsi alasan dari pusat yang lama dalam pemenuhan blanko yang habis dan harapan-harapan yang kurang tepat.

Menurut Dwiyanto,dkk (2008) menyatakan kecukupan berkaitan dengan kinerja pelayanan publik yang buruk, juga disebabkan oleh peraturan yang tidak disosialisasikan kepada pengguna jasa secara jelas dan transparan yang pada akhirnya menimbulkan berbagai penyelewengan peraturan oleh aparat pelayanan.

Menurut Redi Penuju (2004) menyatakan bahwa kecukupan berhubungan dengan budaya organisasi yang di dalamnya ada iklim organisasi meliputi unsur-unsur. I).Tanggung jawab tingkat pendelegasian yang di alami karyawan. 2).Standar harapan tentang kualitas kerja karyawan. 3).Imbalan pengakuan dan penghargaan atas kerja dan penolakan terhadap peyimpangan kerja 4). Keramahan semangat tim, "persaudaraan", saling mempercayai penuh kejujuran. 5). Kesiapan teknologi, penyempurnaa metode kerja. 6).Komunikasi terbuka, kecukupan informasi dan terbuka bagi saran-saran.

Keterbukaan Informasi Publik

Keterbukaan informasi publik merupakan hak warganegara untuk memperoleh informasi publik dijamin oleh UU No 14 tahun 2008 tentang keterbukaan informasi publik, yaitu tercantum pada pasal $28 \mathrm{~F}$ yang berbunyi: "Setiap orang berhak untuk berkomunikasi dan memperoleh informasi untuk mengembangkan pribadi dan lingkungan sosialnya, serta berhak untuk mencari, memperoleh, memiliki, menyimpan, mengolah, dan menyampaikan informasi dengan menggunakan segala jenis saluran yang tersedia".

Adapun informasi adalah keterangan, pernyataan, gagasan, dan tanda-tanda yang mengandung nilai, makna, dan pesan, baik data, fakta maupun penjelasannya yang dapat dilihat, didengar, dan dibaca yang disajikan dalam berbagai kemasan dan format sesuai dengan perkembangan teknologi informasi dan komunikasi secara elektronik ataupun nonelektronik.

Sedangkan informasi publik adalah informasi yang dihasilkan, disimpan, dikelola, dikirim, dan/atau diterima oleh suatu badan publik yang berkaitan dengan penyelenggara dan penyelenggaraan negara dan/atau penyelenggara dan penyelenggaraan badan publik lainnya yang sesuai dengan Undang-Undang ini serta informasi lain yang berkaitan dengan kepentingan publik. 
Sedikit tambahan badan publik adalah lembaga eksekutif, legislatif, yudikatif, dan badan lain yang fungsi dan tugas pokoknya berkaitan dengan penyelenggaraan negara, yang sebagian atau seluruh dananya bersumber dari Anggaran Pendapatan dan Belanja Negara dan/atau Anggaran Pendapatan dan Belanja Daerah, atau organisasi nonpemerintah sepanjang sebagian atau seluruh dananya bersumber dari Anggaran Pendapatan dan Belanja Negara dan/atau Anggaran Pendapatan dan Belanja Daerah, sumbangan masyarakat, dan/atau luar negeri.

\section{METODOLOGI}

Penelitian ini bersifat deskriftif kulitatif yaitu memahami suatu keadaan tentang apa yang terjadi dengan cara dekripsi atau gambaran secara sistematis, yang aktual dan akurat dalam bentuk kata-kata yang di buat dengan data maupun informasi yang di selidiki sebagaimana adanya dan peneliti menggunakan pendekatan deskriptif yang tujuannya untuk menguraikan,menerangkan dan menjelaskan secara mendalam tentang keadaan tersebut.

\section{HASIL DAN PEMBAHASAN}

Berdasarkan hasil pembahasan penelitian tentangkecukupan keterbukaan informasi publik dalam perspektif tata kelola pelayanan E-KTP (elektronik, kartu tanda penduduk) di Kantor Dinas Kependudukan dan Pencatatan Sipil Kabupaten Katingan.

\section{Efisiensi}

Adapun dalam hal ini Efektivitas dan efisiensi sangatlah berhubungan.Apabila kita berbicara tentang efisiensi bilamana kita membayangkan hal penggunaan sumber daya (resources) kita secara optimum untuk mencapai suatu tujuan tertentu. Maksudnya adalah efisiensi akan terjadi jika penggunaan sumber daya diberdayakan secara optimum sehingga suatu tujuan akan tercapai.
Dalam penelitian ini bahwa untuk daya guna dalam keterbukaan informasi publik dalam proses pembuatan E-KTP di Kantor Dinas Kependudukan dan Pencatatan Sipil Kabupaten Katingan itu harus adanya papan informasi di depan kantor agar masyarakat tahu ketika mau pembuatan E-KTP baru karena kehilangan E-KTP misalnya, bahwa untuk daya guna dalam keterbukaan informasi publik dalam proses pembuatan E-KTP di Kantor Dinas Kependudukan dan Pencatatan Sipil Kabupaten Katingan itu tidak sama sekali ada papan informasi sekaligus dari media sosial, web, akun Dinas Kependudukan dan Pencatatan Sipil Kabupaten Katingan yang diberikan tidak berjalan dengan baik, pedahal dari situ agar masyarakat tahu ketika pembuatan E-KTP baru seperti apa-apa saja yang diperlukan.

\section{Kecukupan}

Berdasarkan data yang di peroleh kecukupan pelayanan yang diberikan sudah cukup baik tapi perlu peningkatkan lagi biar lebih baik lagi karena masih banyak masyarakat katingan yang kebingungan dengan sistem pelayanan yang diberikan yang seperti sistem pelayanan dibank ada yang belum ambil loket antri biasanya jika pegawai tidak cepat tanggap terhadap masyarakat dalam melayani sedangkan perataan dalam memberikan keterbukaan informasi publik dalam proses pembuatan E-KTP belum menyeluruh karena masih banyak saya lihat masyarakat Katingan belum mempunyai E-KTP, untuk Kecukupan pelayanan dalam keterbukaan informasi publik dalam proses pembuatan cukup baik pelayanan sekarang menggunakan sistem seperti dibank tapi perlu adanya penikatan karena masih baru merubah sistem pelayanan seperti dibank, untuk ketepatan waktu pembuatan EKTP agar bisa lebih akurat dalam memberikan keterbukaan informasi publiknya, karena kecukupan pelayanan yang diberikan belum memuaskan untuk memberikan keterbukaan informasi publik tanda jadi pembuatan E-KTP tersebut, Dinas Kependudukan dan Pencacatan Sipil Kabupaten Katingan meningkatkan 
infomasi yang menyeluruh mengingat tentang daya guna dalam keterbukaan informasi publik dalam proses pembuatan E-KTP karena ini adalah agar masyarakat lebih mengetahui apa yang terjadi dalam proses pembuatan E-KTP perlu menyediakan papan informasi atau papan pengumuman yang gagal rekam maupun yang sudah rekam dan perlu adannya dari kecamatan yang terkait juga ikut, infomasi itu bisa memberikan daya guna bagi masyarakat yang tinggal jauh dari Kabupaten Katingan baik secara lisan maupun melalui handphone, untuk kecukupan pelayanan cukup baik cuma saja pegawai Dinas Kependudukan dan Pencatatan Sipil Kabupaten Katingan harus memperhatikan keterbukaan informasi publik dalam proses pembuatan E-KTP yang sudah rekaman E-KTP baik yang belum perekaman EKTP dipaparkan di papan pengumuman, untuk kecukupan pelayanan yang sekarang masih belum cukup baik karena masih mencoba meningkatkan pelayanan yang lebih baik lagi kepada masyarakat.

\section{Perataan}

Berdasarkan Hasil penelitian masih banyak saya lihat masyarakat Katingan belum mempunyai E-KTP, dari kecamatan tempat daerah saya tempat tinggal tidak ada informasi yang diberikan oleh Pihak Kecamatan tentang ketetapan waktu informasi jadi pembuatan E-KTP seharusnya dari kecamatan maupun Dinas yang terkait mengerti keadaan masyarakat Dinas Kependudukan dan Pencatatan Sipil Kabupaten Katingan seharusnya memberikan informasi yang akurat tepat waktu tanggal bulan dan tahun seharusnya ditetapkan awal saat perekaman E-KTP jadi masyarkat lebih nyaman, agar kami sebagai masyarakat tidak harus bolak-balik untuk pengambilan jadi pembuatan yang telah jadi, banyak perataan informasi yang di berikan masih belum maksimal, masih banyak masyarakat kabupaten katingan, belum mengetahui E-KTP sudah jadi apa belum kepada masyarakat, memberikan keterbukaan informasi yang memadai seperti halnya bagi yang sudah perekaman ataupun yang gagal rekam sekalipun agar bisa diinformasikan kepada masayarkat melalui media sosial, sosialiasasi, no handphone,dari papan pengumuman, atau pun dari kecamatan yang bersangkutan, masyarakat dari kecamatan lain berkata kurang lebih sama dalam pembuatan E-KTP sangat tidak ada informasi yang diberikan baik untuk meminta no hp saya agar meminfokan bahwa E-KTP saya sudah jadi itu tidak ada sama sekali karena kecukupan pelayanan yang diberikan belum memuaskan untuk memberikan keterbukaan informasi publik tanda jadi pembuatan E-KTP tersebut, perataan informasi yang diberikan tidak menyeluruh sama sekali, sampai akhir dari wawancara saya kurang lebih masyarakat menjawabnya sama, perataan informasi yang tidak merata atau tidak menyeluruh kepada seluruh masyarakat banyak masyarakat yang tidak tahu kapan jadi pembuatan E-KTP nya.

Responsivitas

Daya tanggap pegawai dalam memberikan keterbukaan informasi publik dalam proses pembuatan ini kurang baik karena masih banyak perlu perbaikan masalahnya informasi yang diberikan tidak menyeluruh sedang masyarakat banyak tinggal jauh dari kota kabupaten katingan dalam memberikan informasi yang akurat dan tepat, adapun demikian bahwa untuk respon yang para pegawai Dinas Kependudukan dan Pecatatan Sipil Kabupaten Katingan masih belum baik, menyangkut dalam pemberian informasi dalam proses pembuatan EKTP yang sangat lama jadi pembuatan E-KTP, sebagai masyarakat bertanya-tanya akan pembuatan E-KTP yang sangat lama, daya tanggap pegawai terhadap masyarakat kurang baik karena banyak masyarakat menanyakan kepastian jadi pembuatan E-KTP itu yang dari awal perekaman E-KTP tidak ada pemberitahuan terhadap surat perekaman E-KTP tersebut untuk pengambilan jadi pembuatan E-KTP yang aslinya, karena E-KTP ini untuk memangkas birokrasi bukan malah menyulitkan masyarkat bolak-balik hanya untuk menanyakan kapan jadi pembuatan E-KTP itu saja seperti yang dbihas diatas bahwa sebagai pegawai harus tanggap, responnya yang 
cepat, tanggap dengan keadaan sedemikian rupa bergegas demi kepentingan masyarakat.

\section{Ketepatan}

Ketepan waktu pembuatan E-KTP menjadi tolak ukur dalam proses pembuatan E-KTP, jadi pemberian informasi masih belum optimal kepada seluruh masyarakat Kabupaten Katingan, sebagai masyarakat kami butuh kepastian yang pasti dan akurat yang asal asalan di ucapkan, Pembuatan E-KTP yang hampir dua tahun Sudah E-KTP masyarakat banyak belum jadi-jadi, untuk itu ketepatan informasi yang diberikan belum maksimal.

\section{KESIMPULAN}

Berdasarkan hasil pembahasan dalam penelitian ini, maka dapat disimpulkan bahwa mengenai, kecukupan keterbukaan informasi publik dalam perspektif tata kelola pelayanan E-KTP di Kantor Dinas Kependudukan dan Pencatata Sipil Kabupaten Katingan, belum maksimal dari segi efisiensi, kecukupan, perataan, responsivitas, serta ketepatan waktu. dalam memberikan kecukupan keterbukaan informasi publik dalam perspektif tata kelola pelayanan E-KTP, Hendaknya Dinas Kependudukan dan Pencatatan Sipil Kabupaten Katingan memiliki papan pengumuman tentang data jadi pembuatan E-KTP yang kongkrit yang akurat dan tepat waktu, beberapa data yang di berikan kepada pihak kecamatan yang terkait untuk memberikan menyampaikan informasi tentang ketepatan waktu jadi pembuatan E-KTP, menyampaikan informasi yang aktif di media sosial yang ada kepada masyarakat, maupun memberikan informasi melalui no hp kepada masyarakat tentang jadi pembuatan E-KTP tersebut. Meberikan informasi dengan memaparkan menempelkan informasi pada taransportasi sungai (yang di kenal kalotok) jadi masyarakat bisa tahu kapan jadi pembuatan E-KTP tersebut. 2. Untuk meningkat kecukupan pelayanan yang diberikan, seharusnya masyarakat harus meningkat daya tanggap agar kecukupan pelayanan harus bisa lebih baik lagi meskipun pelayanan yang diberikan Seperti peyanan di bank, maka dari pegawai harus cepat tanggap kepada masyarakat dalam memberikan pelayanan kepada masyarakat. Untuk meningkatkan perataan informasi pelayanan E-KTP dengan memberikan informasi yang menyeluruh kepada masyarakat semaksimal dan memadai, agar informasi dapat di akses oleh seluruh masyarakat kabupaten katingan melalui media sosial yang aktif akun web Dinas Kependudukan dan Pencatatan Sipil Kabupaten Katingan, no Handphone, dan kecamatan yang terkait, dan memberikan keterbukaan informasi publik melalui tranporatasi sungai misalkan (kalotok) agar lebih merata. Untuk meningkatkan responsivitas pegawai hendaknya menambah pegawai yang baik sesuai pada bidangnya dalam menyempaikan informasi dalam perspektif tata kelola pelayanan E-KTP yang cepat tanggap terhadap masyarakat kabupaten katingan dalam menyampaikan informasi publik. Untuk meningkat ketepatan pegawai dalam memberikan kecukupan keterbukaan informasi publik dalam perspektif tata kelola pelayanan E-KTP, agar menentukan jadi pembuatan E-KTP yang akurat dan tepat waktu dalam menyampaikan informasi yang diberikan

\section{REFERENSI}

Dunn, William N. 2003. Pengantar Analisis Kebijakan Publik Edisi Kedua. Yogyakarta: Gadjah Mada University Press.

Irwani. 2016. Pengaruh Kepuasan Kerja Melalui Komitmen Kerja Terhadap Disiplin Kerja Pegawai Negeri Sipil Pada Inspektorat Kota Palangka Raya. Restorica: Jurnal Ilmiah IImu Administrasi Negara dan Ilmu Komunikasi. 2(I): I-8.

Karyadi, K., Nisa, E. 20I5. Pengaruh Penerapan Prinsip Good Governance terhadap Kualitas Pelayanan E-KTP pada Kantor Kependudukan dan Pencatatan Sipil Kabupaten Katingan. Pencerah Publik. I(I):I3-I7.

Mambang, M., Saipul, S. 2016. Kualitas Pelayanan Pembuatan KTP-El Pada Kantor Dinas Kependudukan Dan Pencatatan Sipil Kota 
Palangka Raya Dalam Perspektif Pelayanan Prima. Pencerah Publik. 3(I):53-59.

Panggulu, Y. 2013. Efektivitas Kebijakan Retribusi Pada Dinas Pengelolaan Pasar Kebersihan Dan Pertamanan Di Kabupaten Kepulauan Talaud. Jurnal Administrasi Publik. I (I): I-I0.

Peraturan Bupati Katingan. Nomor 5I tahun 2016. Pedoman Informasi dan Dukumentasi di lingkungan Bupati katingan.

Slamet, Prajudi Atmosudirdjo. 2017. Dasar-dasar IImu administrasi. Jakarta: Ghalia Indonesia.

Suharsaputra,Uhar. 20I4. Metode Penelitian Kuantitatif, Kualitatif, dan Tindakan. Bandung: Refika Aditama.

Suharto, Edi. 2005. Analisis Kebijakan Publik. Bandung :Alfabet.

Sugiyono. 2008. Metode Penelitian Administrasi. Bandung: Alfabeta.

Sugiyono. 2012. Metode Penelitian Kuantitatif, Kualitatif dan R\&D. Bandung: Alfabeta.

Sutrisno Edy. 2009. Manajemen Sumber Daya Manusia. Jakarta: Kencana Pranada Media Group

Sutrisno, Edy. 2010. Budaya Organisasi. Jakarta: Kencana Media Group.

Tjahjanulin Domai. 20II. Sound Governance. Malang: Universitas Brawijaya Press.

Undang-Undang No 14 Tahun 2008 Tentang
$\begin{gathered}\text { Keterbukaan } \\ \text { Indonesia. }\end{gathered}$

